\title{
INCIDENCE OF MALIGNANCY IN SOLITARY THYROID NODULE- A STUDY AT GOVERNMENT GENERAL HOSPITAL, GUNTUR
}

\author{
Mudavatu Bhagavan Naik1, Gali Satyanavamani², Batta Sreekanth ${ }^{3}$
}

1 Professor, Department of Surgery, Guntur Medical College and Government General Hospital, Guntur, Andhra Pradesh. ${ }^{2}$ Assistant Professor, Department of Surgery, Guntur Medical College and Government General Hospital, Guntur, Andhra Pradesh. 3Junior Resident, Department of Surgery, Guntur Medical College and Government General Hospital, Guntur, Andhra Pradesh.

\section{ABSTRACT}

\section{BACKGROUND}

Thyroid gland disorders are the most common endocrine disorders seen in clinical practice and solitary thyroid nodule is one of the common presentations of thyroid disorders.

\section{MATERIALS AND METHODS}

The study was conducted in the Department of General Surgery at Government General Hospital, Guntur district consisting of 116 cases of solitary thyroid nodule in all the surgical units, during the period of 2015 to 2017. The clinical study was done through questionnaires and clinical examination. All patients were investigated with routine and special investigations. Necessary treatment was planned once arrived at a definitive diagnosis of solitary thyroid nodule. Postoperative complications were also included.

\section{RESULTS}

116 cases of clinically solitary nodule of the thyroid treated in Government General Hospital, Guntur during a three-year period (2015 - 2017) have been reviewed. In the present study females outnumbered the males with a male-to-female ratio of 1: 8.66, most of the patients are (i.e. 91 out of 116 ) between 21 and 40 years. Benign nodules constitute about 87.93\% and malignant nodules about $12.06 \%$ of all clinically solitary nodules. Of all the 116 cases of clinically solitary nodules, 60 cases were turned out to be multinodular goitres at exploration or on histopathology. So, only 56 cases were true solitary nodules constituting $48.27 \%$ of clinically solitary nodules.

\section{CONCLUSION}

Thyroid scan carries great diagnostic, therapeutic and prognostic significance in toxic nodular goitre. Recently developed immunohistochemical and genetic techniques for examining FNAB specimens may produce nearly $100 \%$ reliability in the near future. Technical advances in HRUS have benefited the diagnosis of thyroid nodules.

\section{KEY WORDS}

Solitary Nodule, Thyroid, Malignancy, Diagnosis.

HOW TO CITE THIS ARTICLE: Naik MB, Satyanavamani G, Sreekanth B. Incidence of malignancy in solitary thyroid nodule- a study at Government General Hospital, Guntur. J. Evolution Med. Dent. Sci. 2018;7(19):2309-2312, DOI: $10.14260 /$ jemds/2018/520

\section{BACKGROUND}

Thyroid gland disorders are the most common endocrine disorder seen in clinical practice and solitary thyroid nodule is one of the common presentations of thyroid disorders. Definition of Solitary Thyroid Nodule: A discrete swelling in an otherwise impalpable gland is termed isolated or solitary nodule of thyroid.[1]

At autopsy, upto $30 \%$ of thyroid nodules harbour malignant nodules under $1 \mathrm{~cm}$, termed as microcarcinomas. ${ }^{[2]}$ A nodule is more likely to be a carcinoma in males. ${ }^{[3]}$ The major concern relates to the potentiality for malignancy of solitary nodule. Whether nodule size itself is a risk factor for malignancy is controversial. Fine needle aspiration biopsy is the single most important test in the evaluation of patients

'Financial or Other Competing Interest': None.

Submission 10-04-2018, Peer Review 21-04-2018,

Acceptance 24-04-2018, Published 07-05-2018.

Corresponding Author:

Gali Satyanavamani,

Flat No. 509, B-Block

Rishi Valley Homes,

Opp. ITC Near IMA Hall,

Guntur, Andhra Pradesh.

E-mail: dr.satyanavamani@gmail.com

DOI: $10.14260 /$ jemds $/ 2018 / 520$ with thyroid swellings. ${ }^{[4]}$ Ultrasound is one of the easily available investigation for differentiating solid from cystic nodules and for identifying adjacent lymphadenopathy.[5]

The optimal management of a solitary thyroid nodule continues to be a source of controversy, because most surgeons recommend operative intervention and surgery is not always considered by some physicians, advocating either observation or thyroid suppression.

Most patients with a solitary nodule will have a benign lesion; however, thyroid cancer must be considered in all patients. Deciding between conservative management and surgical therapy relies on careful analysis of the clinical findings, risk assessment, imaging and diagnostic testing.[6,7]

Objective of the study was to determine the incidence of solitary nodule and its relation with age and sex and to determine the incidence of adenoma, carcinoma and thyroiditis as causes of solitary nodules of thyroid in Government General Hospital, Guntur.

\section{MATERIALS AND METHODS}

\section{Source of Data}

The study was conducted in the Department of General Surgery at Government General Hospital, Guntur district 
consisting of 116 cases of solitary thyroid nodule in all the surgical units during the period from 2015 to 2017.

\section{Study Design}

Case series.

\section{Method of Collection of Data}

The data was collected from patients admitted with a diagnosis of solitary nodule in the Department of Surgery, GGH, Guntur.

The clinical study was done through questionnaires and clinical examination. All patients were investigated with routine and special investigations. Necessary treatment was planned once arrived to a definitive diagnosis of solitary thyroid nodule. Postoperative complications were also included.

\section{Inclusion Criteria}

Cases admitted to the hospital with a diagnosis of solitary thyroid nodule, irrespective of the sex of the patients.

\section{Exclusion Criteria}

- Children aged less than 12 years.

- Patients of coagulopathy and on anti-coagulant regimen.

- Pregnant women with solitary thyroid nodule.

\section{Statistical Analysis}

The details of all cases are summarised in the master chart and results of the study have been analysed in detail. Statistical analysis was done using Microsoft Excel 2010 version. Data was presented in percentages and proportions.

\section{RESULTS}

Review of the statistics of patients with clinically solitary nodules admitted and treated in the surgical wards of Government General Hospital, Guntur during a two-year period (2015 - 2017) is made and certain conclusions are drawn from the same.

Total number of thyroid diseases admitted in all the surgical units during the above period- 550. Study done for $116(21.09 \%)$.

In the present series, females outnumbered the males. There are 12 males and 104 females giving a male-to-female ratio of 1: 8.66, most of the patients are (i.e. 91 out of 116) between 20 and 39 years with a peak incidence in $30-39$ years' group. Youngest patient is 19 years. Oldest patient is 58 years.

Majority of the solitary nodules are located in right lobe. In the present study $51.72 \%$ of solitary nodules were in the right lobe, $39.65 \%$ in the left lobe and $8.62 \%$ in the isthmus.

The duration of symptoms ranged from 3 months to more than one year. 43 patients complained of a swelling of more than one-year duration. In all the 12 patients with proven malignancy symptoms were present for more than one-year duration.

\section{Modes of Presentation}

In all cases, the presenting complaint was a swelling in the region of the thyroid. But they sought advice for different reasons. Most of the patients in the younger age group, i.e. those below 30 years of age had no other symptoms apart from the swelling and sought advice because of the disfigurement. Pressure symptoms were noted in only 15 cases. Out of whom 8 cases had dysphagia, 3 had dyspnoea and in 4 cases there was change in voice.

Among 8 cases with Dysphagia, 2 cases were diagnosed with malignancy. All the patients with dyspnoea had benign solitary nodules. Of the 4 patients with change in voice, one patient had a huge benign nodule and the other three had malignant nodules.

Size and consistency were varying from case to case. Smallest size was $2 \times 1 \mathrm{~cm}$ and largest size was $8 \times 6 \mathrm{~cm}$.

Regarding consistency it was soft in 38 cases, firm in 70 cases and hard in 8 cases.

Of the 38 patients with soft nodules, 2 had malignant nodules and the other 36 had benign nodules. Of the 70 patients with firm nodules, 2 had malignant nodules and the others had benign nodules. All the patients presenting with hard nodules had malignancy.

Deviation of the trachea was observed in 46 cases. Deviation to the right was found in 20 cases (43.48\%) and to the left in 26 cases (56.52\%).

Toxicity was observed in only 2 cases of the total solitary nodules constituting about $1.72 \%$.

Indirect laryngoscopy was done in all cases. Vocal cord palsy was present in 3 cases. All these 3 patients had malignant nodules.

\section{Ultrasound Features}

Ultrasonogram of the thyroid was done in all cases. Of the 116 patients who underwent ultrasonogram showed 3 types of solitary nodules. In half the proportion of the cases (50\%), it was solid followed by cystic in $34.48 \%$ and mixed in $15.52 \%$

\begin{tabular}{|c|c|c|c|c|c|}
\hline 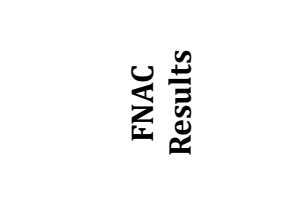 & 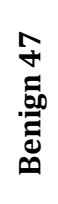 & 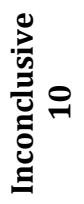 & 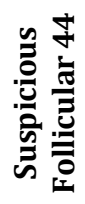 & 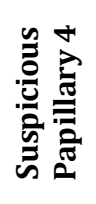 & 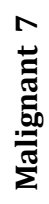 \\
\hline $\begin{array}{l}\text { Final histological } \\
\text { diagnosis- Cancer }\end{array}$ & 1 & 2 & 1 & 3 & 7 \\
\hline \multicolumn{6}{|c|}{$\begin{array}{c}\text { Table 1. Distribution of Results of Fine-Needle Aspiration } \\
\text { Cytology }\end{array}$} \\
\hline
\end{tabular}

The above table shows correlation of fine needle aspiration cytology and final histological diagnosis. 100\% accuracy was found in malignant cytology.

\begin{tabular}{|c|c|c|}
\hline & No. of Cases & Percentage \\
\hline $\begin{array}{l}\text { Total number of clinically solitary } \\
\text { thyroid nodules studied }\end{array}$ & 116 & 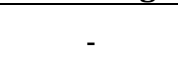 \\
\hline Benign nodules (Total) & 102 & $87.93 \%$ \\
\hline Multinodular & 60 & $51.72 \%$ \\
\hline Toxic nodules & 02 & $1.72 \%$ \\
\hline Variants of adenoma & 30 & $25.86 \%$ \\
\hline Hashimoto's thyroiditis & 10 & $8.62 \%$ \\
\hline Malignant nodules & 14 & $12.06 \%$ \\
\hline Papillary carcinoma & 11 & $\begin{array}{c}78.57 \% \text { of } \\
\text { malignant } \\
\text { nodules }\end{array}$ \\
\hline Follicular carcinoma & 02 & $14.28 \%$ \\
\hline Anaplastic carcinoma & 01 & \\
\hline Medullary carcinoma & 0 & \\
\hline Lymphoma & 0 & \\
\hline \multicolumn{3}{|c|}{ Table 2. Pathological Diagnosis } \\
\hline
\end{tabular}


So, the benign nodules constitute about $87.93 \%$ and malignant nodules $12.06 \%$ of all clinically solitary nodules. Of all the 116 cases of clinically solitary nodules, 60 cases were turned out to be multinodular goitres at exploration or on histopathology. So only 56 cases were true solitary nodules constituting $48.27 \%$ of clinically solitary nodules.

\section{DISCUSSION}

116 cases of clinically solitary nodules of the thyroid treated in Government General Hospital, Guntur during a three-year period (2015 - 2017) have been reviewed. A detailed study of 12 cases of clinically solitary nodules of thyroid is made. In the present study, females outnumbered the males with a male-to-female ratio of $1: 8.66$. Most of the patients are (i.e. 91 out of 116) between 21 and 40 years with a peak incidence in 30 - 39 years' group. The results are consistent with the study done by SM Nazmul Huque et al[8] with 118 patients of STN. Majority of the patients were within $21-40$ years' age group with female predominance. In thyroid malignancy, male and female ratio was 1: 1.75.64.

In the present study, in all cases the presenting complaint was a swelling in the region of the thyroid. But they sought advice for different reasons. Most of the patients in the younger age group, i.e. those below 30 years of age had no other symptoms apart from the swelling and sought advice because of the disfigurement. Pressure symptoms were noted in only 15 cases. The results were similar to the other studies.

Study done by Nirav Priyadarshi et al consists of 35 cases of solitary thyroid nodule. Majority of the patients is between 30 - 49 years of age. Female: male ratio is about 7.7. After swelling, pain over swelling was the second most common presentation (5.8\%). Most common benign pathology is follicular adenoma (24\%) and malignancy is papillary carcinoma $(11.42 \%)$ and follicular carcinoma (11.42\%). Commonest surgery performed was Hemithyroidectomy in 19 (54.28\%) cases. Majority of patients are euthyroid on presentation. FNAC is the first investigation of choice. USG is a useful diagnostic aid. Modified neck dissection is advised for patients with enlarged nodes in papillary carcinoma and for those postop patients who are diagnosed to have malignancy with lymph node metastasis.[9]

Of the 116 patients who underwent ultrasonogram showed 3 types of solitary nodules. In half the proportion of the cases (50\%), it was solid followed by cystic in $34.48 \%$ and mixed in $15.52 \%$. Correlation of Fine needle aspiration cytology and final histological diagnosis, 100\% accuracy was found in malignant cytology.

Study by Safa Mezher AL-Obaidi et al on the utility and efficacy of FNAC in the diagnosis of solitary thyroid nodule showed a sensitivity of $83.3 \%$ and specificity of $100 \%$ correlation of FNAC with HPE. The cytological diagnosis of benign nodule were confirmed in 80 (96\%) of the 83 patients and were disputed in 3 cases (3.13\%), which was shown to be malignant. In 26 cytological suspicious cases, HPE revealed benign lesion in 18 cases and malignant lesion in 8 cases. All 13 malignant interpretations on cytology were confirmed by HPE. All 8 inadequate specimens on cytology were shown to be benign on HPE.[10]

The incidence of malignancy in the present series is $12.06 \%$. HS Sachdeva[11] reported $6.8 \%$ incidence of malignancy and Richard D Liechty $17.9 \% .{ }^{[12]}$
The incidence of Hashimoto's thyroiditis alone is $8.62 \%$ in the present series which is compared to other series. 1.9\% HS Sachdeva,[11] 8.9\% Richard D Liechty 5.2\%.[12] In these series all varieties of thyroiditis are put together and the incidence of Hashimoto's thyroiditis is not separately mentioned.

\section{CONCLUSION}

Certain conclusions are drawn from this study. The femalemale ratio is 8.66: 1 . The peak age incidence is in $30-39$ years' group. Most common presentation is a swelling in the region of thyroid. Majority of the patients with change in voice have malignant nodules as clinical solitary nodules. All hard solitary nodules are malignant nodules.

Incidence of multinodularity on surgical exploration or on histopathology is $51.72 \%$. So, the incidence of true solitary nodules is $48.28 \%$. Most of the solitary nodules are benign constituting of $89.16 \%$. The incidence of malignancy being $12.06 \%$. Adenoma is the most common pathological type of a true solitary nodule. Papillary carcinoma is the most common malignant variant encountered. The incidence of Hashimoto's thyroiditis in clinical solitary nodules is $8.62 \%$.

FNAC is a very reliable and powerful screening method in the preoperative diagnosis of STN with high specificity and sensitivity, and can differentiate those thyroid nodules which require surgery or not. Combined use of FNAC, thyroid scan and ultrasonography can detect them with $90 \%$ accuracy.

Thyroid scan carries great diagnostic, therapeutic and prognostic significance in toxic nodular goitre. Recently developed immunohistochemical and genetic techniques for examining FNAB specimens may produce nearly 100\% reliability in the near future. Technical advances in HRUS have benefited the diagnosis of thyroid nodules.

\section{REFERENCES}

[1] Dudeley N, Jmoris P, Molt RA. Oxford text of surgery. Chapter - 11. 1. Solitary Thyroid Nodule 1994;1:1-29.

[2] Ito Y, Miyauchi A. A therapeutic strategy for incidentally detected papillary microcarcinoma of the thyroid. Nat Clin Pract Endocrinol Metab 2007;3(3):240-8.

[3] Boelaert K, Horacek J, Holder RL, et al. Serum thyrotropin concentration as a novel predictor of malignancy in thyroid nodules investigated by fineneedle aspiration. J Clin Endocrinol Metab 2006;91(11):4295-301.

[4] Bhansali SK, Gupta R. Current management of solitary nodule of thyroid. 2002;8:197-204.

[5] Marqusee E, Benson CB, Frates MC, et al. Usefulness of ultrasonography in the management of nodular thyroid disease. Ann Intern Med 2000;133(9):696700 .

[6] Cooper DS, Doherty GM, Haugen BR, et al. Revised American Thyroid Association management guidelines for patients with thyroid nodules and differentiated thyroid cancer. Thyroid 2009;19(11):1167-214.

[7] Castro MR, Gharib H. Continuing controversies in the management of thyroid nodules. Ann Intern Med 2005;142(11):926-31.

[8] Huque SMN, Ali MI, Md. Huq M, et al. Histopathological pattern of malignancy in solitary thyroid nodule. Bangladesh J Otorhinolaryngol 2012;18(1):5-10. 


\section{Jemds.com}

[9] Priyadarshi N, Mistry D, Kharadi N. Study of management of solitary thyroid nodule. International Journal of Science and Research (IJSR) 2013;2(3):18184.

[10] AL-Obaidi SM, Zwain AKM, Zaini HH. Comparative study of fine needle aspiration cytology and ultrasonography in the management of solitary thyroid nodule. The Iraqi Postgraduate Medical Journal 2006;5(1):68-73.

\section{Original Research Article}

[11] Sachdeva HS, Chowdhary GC, Bose MS. Thyroid lymphography. Arch Surg 1974;109(3):385-7.

[12] Liechty RD, Stoffel PT, Zimmerman DE. Solitary thyroid nodule. Arch Surg 1977;112(1):59-61. 